\title{
Colonization of Tomato Varieties by Beauveria bassiana Isolates in the Screen House
}

\author{
C. A. Omukoko ${ }^{1}$, L. Turoop ${ }^{2}$ \\ ${ }^{1}$ Department of Horticulture, Jomo Kenyatta University of Agriculture and Technology, Nairobi, Kenya and \\ Chuka University, Chuka, Kenya \\ ${ }^{2}$ Department of Horticulture, Jomo Kenyatta University of Agriculture and Technology, Nairobi, Kenya
}

\begin{abstract}
Tomato, Lycopersicon esculentum Mill. (Solanales: Solanaceae), is a major vegetable crop cultivated worldwide. Production has increased over the years, in most parts of the world, however decline in yields in Kenya has been due to environmental stresses, declining soil fertility, poor crop management and low quality seeds. Pest and disease pressure has also increased, reducing the yields. Chemical control has been widely used over the years but cases of resistance have developed. There is need to seek alternative measures such as biological control agents to complement existing measures. Beauveria bassiana has been known to control insects pests, diseases and also establish as an endophyte in a variety of plant species. Five isolates IC 283, IC 279, IC 273, IC 10 and IC 35 were tested using seed inoculation in the screen house to establish their endophytic association in three tomato varieties Cal J, Kilele and Anna. Beauveria bassiana isolate IC 35 was able to colonize between 3 to $6 \%$ of leaves, stems and roots of the three tomato varieties. All the other four isolates were undetectable in all three plant parts of the varieties tested confirming no colonization.
\end{abstract}

Keywords: Fungal Entomopathogen, Lycopersicon esculentum, Endophytes, Biological control

\section{Introduction}

Tomato, Lycopersicon esculentum Mill. (Solanales: Solanaceae), is a major vegetable crop cultivated worldwide (Rice, 1987). Production has increased over the years to over 200 million metric tons in 2014 and occupied an area of approximately 6 million hectares (FAO, 2015). Tomato contains minerals and vitamins and is mainly eaten raw in salads or cooked in stews to make soups (Varela et al., 2003). Tomato production in Kenya has been on the decline due to environmental stresses, declining soil fertility, poor crop management and low quality seeds (KHDP, 2008). Pest and disease pressure has also increased, reducing the yields (FAO, 2003). The arthropod pests of economic importance include the red spider mites, Tetranychus evansi. Baker \& Pritchard (Acarina: Tetranychidae), African bollworm, Helicoverpa armigera Hübner. (Lepidoptera: Noctuidae), whiteflies, Bemisia tabaci Gennadius. (Hemiptera: Aleyrodidae) and Aphis gossypii Glover (Homoptera: Aphididae). Common species of spider mites in Kenya include Tetranychus evansi Baker and Pritchard, Tetranychus urticae Koch and Tetranychus cinnabarinus Boisduval (Knapp, 2002). The population build-up of spider mites is favored by hot and dry tropical weather conditions (Varela et al., 2003).

Farmers especially in Africa largely depend on expensive synthetic miticides to control $T$. evansi, but pesticide applications are frequently ineffective (Maniania et al., 2008). The excessive and inappropriate use of miticides has resulted in ecological problems, affecting non-target organisms, promoting the development of miticide resistance and posing health risks to farmers and consumers (Wekesa, 2008). High costs have also limited the utilization of chemical control measures (Shetlar, 2000). Biological control against $T$. evansi has included the use of predators or pathogens. The introduction of natural enemies especially predatory mites of the family Phytoseiidae has been successful in the control of other spider mites but have not been effective to T. evansi, especially in Africa (Maniania et al., 2008). Entomopathogenic fungi such as B. bassiana and $M$. anisopliae have gained considerable attention as biological control agents for most agricultural pests (Kaaya and Hassan, 2000).

Isolates of Beauveria bassiana have been tested against Tetranychus evansi and found to be highly virulent suggesting potential for their utilization in the management of the tomato red spider mite, Tetranychus evansi (Wekesa et al., 2005). Beauveria bassiana is sensitive to sunlight, high temperature, soil amendments, organic matter and moisture levels, which affect its efficacy and persistence. Fungal establishment may thus be reduced when applied in hot, sunny conditions or in younger stands with open canopies (Nankinga, 1998). There is therefore need to improve on the mechanisms of delivery such as endophytes.

B. bassiana is not commonly reported as a natural endophyte, but its use as an artificial endophyte in controlling insect pests and plant diseases has been documented (Posada and Vega, 2006). Most fungi colonize plants as parasites or symbionts. However, B. bassiana, colonization in plants provides a unique relationship because it has not been documented as a plant parasite (Akello, 2008). Beauveria bassiana has been recovered as an endophyte from several plant species. Successful introduction has also occurred in plants such as maize (Wagner and Lewis, 2000), cacao (Posada and Vega, 2006), date palm (Gómez-Vidal et al., 2009), opium poppy (Quesada-Moraga et al., 2006), banana (Akello et al., 2007), coffee (Posada et al., 2007), sorghum (Tefera and Vidal, 2009), jute (Biswas et al., 2012), bean (Mutune et al., 2016), grapevine (Jaber, 2015), radiate pine (Brownbridge et al., 2012), wheat, cotton, bean, pumpkin and tomato (Gurulingappa et al., 2010). Studies with several tomato have established $B$. bassiana endophytic growth and colonization (Ownley et al., 2004). The objective of this

Volume 6 Issue 7, July 2017 www.ijsr.net 


\section{International Journal of Science and Research (IJSR) \\ ISSN (Online): 2319-7064}

Index Copernicus Value (2015): 78.96 | Impact Factor (2015): 6.391

study was to determine endophytic colonization of $B$. bassiana isolates on different tomato varieties in the screen house.

\section{Materials and methods}

\section{Fungal culture}

The Beauveria bassiana isolates IC 283, IC 279, IC 273, IC 10 and IC 35 were obtained from the ICIPE's Arthropod Germplasm Centre, Nairobi, Kenya. They were cultured on Sabouraud Dextrose Agar (SDA) medium amended with $0.05 \mathrm{~g}$ chloramphenicol antibiotics to minimize the bacterial contamination and incubated for three weeks at $27^{\circ} \mathrm{C}$ (Inglis et al., 1996). Conidia were gently scrapped from fungal cultures and suspended in $10 \mathrm{ml}$ sterile distilled water in 20$\mathrm{ml}$ universal bottle containing $0.01 \%$ Tween-20 and glass beads. The conidial suspension was vortexed for 5 minutes to produce a homogenous conidial suspension. From the stock solution a concentration of $1 \times 10^{9}$ conidia $\mathrm{ml}^{-1}$ was prepared since the standard concentration of $1 \times 10^{8}$ from preliminary studies did not establish well in the tomato varieties. The viability of conidia was assessed prior to bioassays by spread-plating $0.1 \mathrm{~mL}$ of $3 \times 10^{6}$ conidia $\mathrm{mL}^{-1}$ onto 90-mm Petri dishes containing SDA (Goettel and Inglis, 1997). The plates were incubated at $27 \pm 2{ }^{\circ} \mathrm{C}$ and were examined after 16-20 hours under the compound microscope ( $\times 40$ magnifications). Conidia were considered as germinated when the germ tube was twice the diameter of the conidium. The experiment was replicated four times. In viability tests, over $90 \%$ of conidia germinated for all the plates.

\section{Tomato plants}

Tomato plants, (Lycopersicon esculentum varieties Cal-J, Kilele and Anna) that were used in this study were raised in the Screen house in JKUAT. Cal-J is highly susceptible to red spider mites but very common in among farmers; Kilele and Anna are new popular hybrids among farmers.

\section{Seed inoculation and colonization}

Seeds of Cal-J, and two hybrids (Kilele and Anna) cultivars were surface-sterilized in $70 \%$ ethanol for $1 \mathrm{~min}$ and then in $1.5 \%$ sodium hypochlorite solution for $3 \mathrm{~min}$. They were washed three times with sterile distilled water and blot dried on sterile paper towels to remove the excess water. The last rinse water was plated out to assess the effectiveness of the surface sterilization procedure. Inoculation was carried out by soaking seeds in conidial suspension $(10 \mathrm{ml})$ of IC 283 , IC 279, IC 273, IC 10 and IC 35 at the concentration of $1 \times 10^{9}$ conidia $\mathrm{ml}^{-1}$ for 2 hours. Mixtures were hand stirred at a 30 minutes interval until the seed were uniformly coated (Powell et al., 2009). Control seeds were soaked in sterile distilled water containing $0.01 \%$ Tween-20 for 2 hours. The seeds were then removed and placed in pots filled with sterilized soil. There were 8 individual plants for all the isolates and for their respective control. The pots containing the seedlings were grown in the screenhouse at $25 \pm 2^{\circ} \mathrm{C}$ and $70 \%-80 \%$ RH for 6 weeks. The endophytic colonization by $B$. bassiana on tomato plant was examined every two weeks after inoculation through destructive sampling of tomato plants. Plants were carefully removed from the pots and washed with tap water and surface-disinfected by submersing them in $70 \%$ ethanol for $15 \mathrm{~s}$, followed by $3 \mathrm{~min}$ in $1.85 \%$ sodium hypochlorite and rinsed 3 times in sterile distilled water. To determine the effectiveness of the disinfecting process the final rinse water was plated on SDA as described early. Plants were dried on sterile paper towels and tissues from leaves, shoots and roots were cut into 4 $\mathrm{mm}^{2}$ sections with a sterile scalpel and about 5 of them were placed on Petri dishes containing SDA medium. Four plates were cultured for each tissue (roots, shoots and leaves) and for each treatment including the control. They were allowed to sporulate for two weeks in the laboratory and then identified as $B$. bassiana based on its morphological characteristics of the inoculated isolate. For each plant part, percent colonization was calculated as number of sections exhibiting $B$. bassiana outgrowth per total number of sections (Fisher and Petrini, 1987).

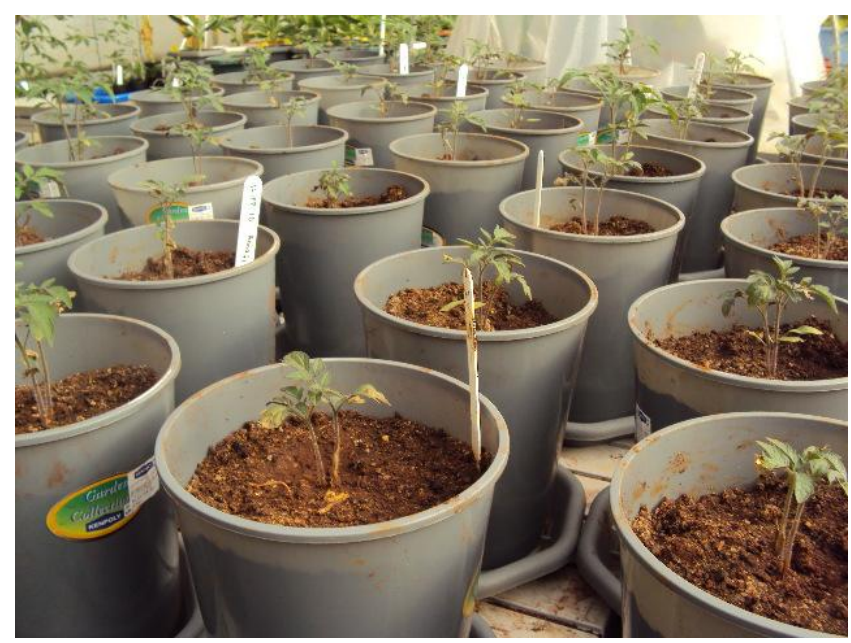

Plate 1: Three weeks old tomato plants in the screen house

\section{Data analysis}

Colonization frequency (CF) was calculated as described by (Fisher and Petrini, 1987). The proportion of fungal colonization per plant part was subjected to ANOVA and means were separated using SNK (Student-Newman-Keuls) (Institute, 1999).

\section{Results}

\section{Endophytic colonization of $B$. bassiana on tomato varieties}

B. bassiana isolate IC 35 was able to colonize root, stem and leaves of all the tomato varieties in the screen house. All the other four isolates were undetectable in all three plant parts of the varieties tested confirming no colonization. However, there were no significant differences in levels of colonization among tomato varieties on stem $(\mathrm{F}=1.7, \mathrm{DF}=$ $2, \mathrm{p}=0.186)$, roots $(\mathrm{F}=2.0, \mathrm{DF}=2, \mathrm{p}=0.127)$ and leaves $(\mathrm{F}=0.28, \mathrm{DF}=2, \mathrm{p}=0.752)$ in all the tested tomato (Fig. 1). For example in Anna, there was no significance difference in colonization among the various plant parts, in leaves $4.5 \%$, compared to stem $5 \%$ and roots $3.3 \%$. Colonization was slightly higher numerically in the leaves $(5.8 \%)$ compared to the stem $(2.9 \%)$ and roots $(3.3 \%)$ in $\mathrm{Cal}$ $\mathrm{J}$ variety. In Kilele, colonization was highest in leaves $(4.8 \%)$ and followed by stem (3.4\%) and roots (1\%) (Fig. 1). There was no colonization of plant parts of Anna, Cal J and Kilele varieties under control treatment.

\section{Volume 6 Issue 7, July 2017 www.ijsr.net}



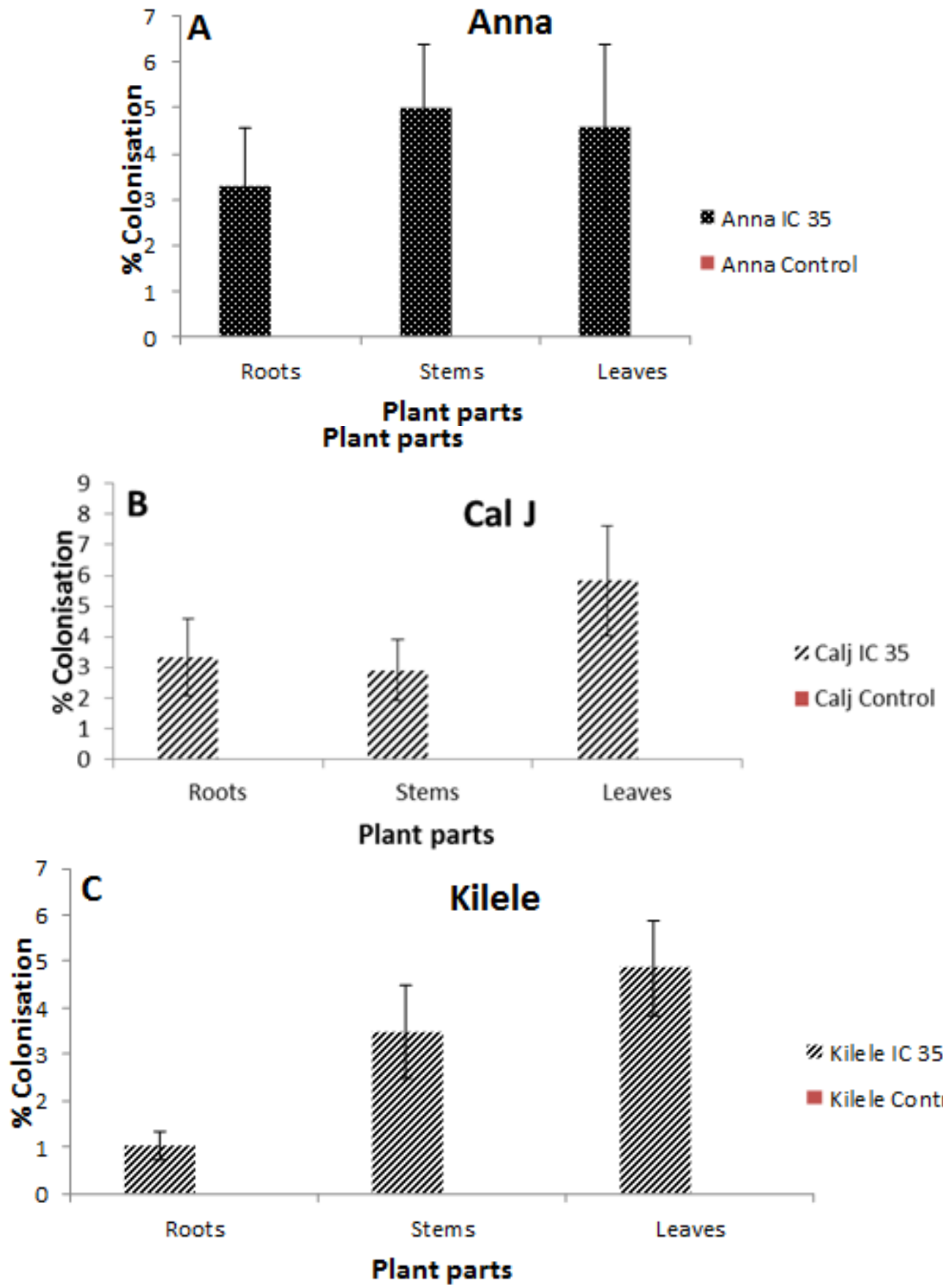

\% Kile le IC 35

- Kile le Control

Figure 1: Colonization of different parts of tomato varieties by Beauveria bassiana isolates ICIPE 35 (A) Anna F1 hybrid (B) Cal J open pollinated (C) Kilele F1 hybrid.

\section{Discussion}

Beauveria bassiana IC 35 was able to colonize the different parts of plants (root, stem and leave) of the three tomato varieties of Anna, Kilele and $\mathrm{Cal} \mathrm{J}$ following seed inoculation in the screenhouse. It was later isolated from the leaves, stem and leaves of these varieties for up six weeks in the screenhouse and identified based on morphology and microscopic observations (Humber, 1997).

The delivery of fungal entomopathogens as endophytes bypasses the limitations imposed by their direct use especially foliar spray where they are affected by UV radiation, varying condition of temperature and humidity that frequently reduces conidial viability (Vega et al., 2012). Once established in the plant system, these endophytes provide plant protection against pests, lower operation costs because there no repeat applications and guarantees efficacy because the fungus is protected against abiotic factors.

In our study seed inoculation was used and the fungus was able to translocate within the various plant parts. Several inoculation methods have also been tested to introduce fungal entomopathogens into plants and they all have different success rates; they include foliar spray, stem injection, soil drench and root dip (Akello et al., 2007; Brownbridge et al., 2012; Posada et al., 2007; Tefera and Vidal, 2009). Several authors who focused on seed treatment established that $B$. bassiana can systemically colonize tissues of different host plants (Akutse et al., 2013; Brownbridge et al., 2012; Tefera and Vidal, 2009). Colonization of plants by entomopathogens can take several

Volume 6 Issue 7, July 2017 www.ijsr.net 


\section{International Journal of Science and Research (IJSR) \\ ISSN (Online): 2319-7064}

Index Copernicus Value (2015): 78.96 | Impact Factor (2015): 6.391

pathways which all depends on the fungi and the plant in question; however systemic spread has been advocated by most authors (Bing and Lewis, 1991). This supports previous studies which attributed this to passive movement within the xylem since fungal hyphae could be observed within the vascular tissues (Bing and Lewis, 1992).

The tested varieties of Anna, Kilele and Cal J colonization varied depending on the plant parts, this depends on the genotype-specific interaction between tomato varieties and endophytes (Saikkonen et al., 2010) as well as the method used for detection of endophytic plant colonization (Hyde and Soytong, 2008). Culture-based detection, used in most studies, does not detect all endophytic fungi in colonized plant tissues as compared to molecular- based detection (Jaber, 2015; Posada and Vega, 2005).

Anna and Kilele varieties recorded low colonization in roots as compared to $\mathrm{Cal} \mathbf{J}$ which had low colonization in the stem. In most studies done low colonization rate of Beauveria bassiana as an endophyte in plant tissues may due to plants regulating their defence metabolism, perceiving the endophytic organisms as adverse pathogens (Ownley et al., 2008; Vidal and Jaber, 2015). When endophytes start to grow systemically from the point of inoculation to other plant parts through intercellular spaces and vascular xylem elements, they inevitably have to confront other fungi already established within the plant (Posada and Vega, 2006; Quesada-Moraga et al., 2006; Wagner and Lewis, 2000).

Endophytic fungi are also known to be specific to the different plant tissues because they adapt to the conditions in that plant part (Fisher and Petrini, 1987). Consequently, the preferential tissue colonization displayed by $B$. bassiana within host plants could be due to the differences in the microbial, biochemical, and physiological conditions of different plant tissues(Hu and Leger, 2002). The differences in the endophytic colonization by Beauveria bassiana in tomato varieties may also be due to innate characteristics of the tested isolate (Posada et al., 2007).

\section{Conclusion}

This study revealed significant additional data of the endophytic association between $B$. bassiana and tomato varieties in the screen house. The four isolates that did not establish endophytic relationships can be further tested on other tomato varieties as well other crops. IC 35 will be used for further trials in field experiments.

\section{Acknowledgments}

This work was funded by NACOSTI Research Funds for postgraduate students. The Authors are also grateful to ICIPE for providing the isolates that were used in this study.

\section{References}

[1] Akello, J., Dubois, T., Gold, C. S., Coyne, D., Nakavuma, J., and Paparu, P. (2007). Beauveria bassiana (Balsamo) Vuillemin as an endophyte in tissue culture banana (Musa spp.). Journal of invertebrate pathology 96, 34-42.

[2] Akutse, K., Maniania, N., Fiaboe, K., Van den Berg, J., and Ekesi, S. (2013). Endophytic colonization of Vicia faba and Phaseolus vulgaris (Fabaceae) by fungal pathogens and their effects on the life-history parameters of Liriomyza huidobrensis (Diptera: Agromyzidae). Fungal Ecology 6, 293-301.

[3] Bing, L. A., and Lewis, L. C. (1991). Suppression of Ostrinia nubilalis (Hübner)(Lepidoptera: Pyralidae) by endophytic Beauveria bassiana (Balsamo) Vuillemin. Environmental entomology 20, 1207-1211.

[4] Bing, L. A., and Lewis, L. C. (1992). Endophytic Beauveria bassiana (Balsamo) Vuillemin in corn: the influence of the plant growth stage and Ostrinia nubilalis (Hübner). Biocontrol Science and Technology 2, 39-47.

[5] Biswas, C., Dey, P., Satpathy, S., and Satya, P. (2012). Establishment of the fungal entomopathogen Beauveria bassiana as a season long endophyte in jute (Corchorus olitorius) and its rapid detection using SCAR marker. BioControl 57, 565-571.

[6] Brownbridge, M., Reay, S. D., Nelson, T. L., and Glare, T. R. (2012). Persistence of Beauveria bassiana (Ascomycota: Hypocreales) as an endophyte following inoculation of radiata pine seed and seedlings. Biological control 61, 194-200.

[7] FAO (2003). World Agriculture Information Centre Data base, . Rome,Italy.

[8] FAO, I. (2015). WFP, 2014: The state of food insecurity in the world. FAO, Rome.

[9] Fisher, P., and Petrini, O. (1987). Location of fungal endophytes in tissues of Suaeda fruticosa: a preliminary study. Transactions of the British Mycological Society 89, 246-249.

[10] Goettel, M., and Inglis, G. (1997). Fungi: Hyphomycetes. In "Manual of Techniques in Insect Pathology"(LA Lacey, Ed.) pp. 213-249. Academic Press, London.

[11] Gómez - Vidal, S., Salinas, J., Tena, M., and Lopez - Llorca, L. V. (2009). Proteomic analysis of date palm (Phoenix dactylifera L.) responses to endophytic colonization by entomopathogenic fungi. Electrophoresis 30, 2996-3005.

[12] Gurulingappa, P., Sword, G. A., Murdoch, G., and McGee, P. A. (2010). Colonization of crop plants by fungal entomopathogens and their effects on two insect pests when in planta. Biological control 55, 34-41.

[13] Hu, G., and Leger, R. J. S. (2002). Field studies using a recombinant mycoinsecticide (Metarhizium anisopliae) reveal that it is rhizosphere competent. Applied and Environmental Microbiology 68, 6383-6387.

[14] Humber, R. A. (1997). Fungi: identification. Manual of techniques in insect pathology. Academic, San Diego, CA, 153-185.

[15]Hyde, K., and Soytong, K. (2008). The fungal endophyte dilemma. Fungal Divers 33, e173.

[16] Inglis, G. D., Johnson, D. L., and Goettel, M. S. (1996). An Oil-Bait Bioassay Method Used to Test the Efficacy ofBeauveria bassianaagainst Grasshoppers. Journal of invertebrate pathology 67, 312-315.

[17] Institute, S. A. S. (1999). "SAS/STAT user's guide, version 8 ," SAS Institute.

\section{Volume 6 Issue 7, July 2017 www.ijsr.net}




\section{International Journal of Science and Research (IJSR) \\ ISSN (Online): 2319-7064 \\ Index Copernicus Value (2015): 78.96 | Impact Factor (2015): 6.391}

[18] Jaber, L. R. (2015). Grapevine leaf tissue colonization by the fungal entomopathogen Beauveria bassianas. 1 . and its effect against downy mildew. BioControl 60, 103-112.

[19] KHDP (2008). Keeping small holders in Business. pp. 10.

[20] Knapp, M. (2002). Important mite crop pest in Africa. In "XI International Congress of Acarology, Merida, Mexico".

[21] Mutune, B., Ekesi, S., Niassy, S., Matiru, V., Bii, C., and Maniania, N. K. (2016). Fungal endophytes as promising tools for the management of bean stem maggot Ophiomyia phaseoli on beans Phaseolus vulgaris. Journal of Pest Science 89, 993-1001.

[22] Ownley, B. H., Griffin, M. R., Klingeman, W. E., Gwinn, K. D., Moulton, J. K., and Pereira, R. M. (2008). Beauveria bassiana: endophytic colonization and plant disease control. Journal of invertebrate pathology 98, 267-270.

[23] Ownley, B. H., Pereira, R. M., Klingeman, W. E., Quigley, N. B., Leckie, B. M., Lartey, R., and Caesar, A. (2004). Beauveria bassiana, a dual purpose biocontrol organism, with activity against insect pests and plant pathogens. Emerging concepts in plant health management 2004, 255-269.

[24] Posada, F., Aime, M. C., Peterson, S. W., Rehner, S. A., and Vega, F. E. (2007). Inoculation of coffee plants with the fungal entomopathogen Beauveria bassiana (Ascomycota: Hypocreales). Mycological research 111, 748-757.

[25] Posada, F., and Vega, F. E. (2005). Establishment of the fungal entomopathogen Beauveria bassiana (Ascomycota: Hypocreales) as an endophyte in cocoa seedlings (Theobroma cacao). Mycologia 97, 11951200.

[26] Posada, F., and Vega, F. E. (2006). Inoculation and colonization of coffee seedlings (Coffea arabica L.) with the fungal entomopathogen Beauveria bassiana (Ascomycota: Hypocreales). Mycoscience 47, 284-289.

[27] Powell, W. A., Klingeman, W. E., Ownley, B. H., and Gwinn, K. D. (2009). Evidence of endophytic Beauveria bassiana in seed-treated tomato plants acting as a systemic entomopathogen to larval Helicoverpa zea (Lepidoptera: Noctuidae). Journal of Entomological Science 44, 391-396.

[28] Quesada-Moraga, E., Landa, B., Muñoz-Ledesma, J., Jiménez-Diáz, R., and Santiago-Alvarez, C. (2006). Endophytic colonisation of opium poppy, Papaver somniferum, by an entomopathogenic Beauveria bassiana strain. Mycopathologia 161, 323-329.

[29] Rice, R. P., Rice,L.W., and Tindall,H. D. (1987). "Fruit and Vegetable Production in Africa.," Macmillan Publishers, U.K.

[30] Saikkonen, K., Saari, S., and Helander, M. (2010). Defensive mutualism between plants and endophytic fungi? Fungal Diversity 41, 101-113.

[31] Tefera, T., and Vidal, S. (2009). Effect of inoculation method and plant growth medium on endophytic colonization of sorghum by the entomopathogenic fungus Beauveria bassiana. BioControl 54, 663-669.

[32] Varela, A., Seif, A., and Löhr, B. (2003). A guide to IPM in tomato production in Eastern and Southern Africa. ICIPE. Science Press, Nairobi. 128pp.
[33] Vidal, S., and Jaber, L. R. (2015). Entomopathogenic fungi as endophytes: plant-endophyte-herbivore interactions and prospects for use in biological control. Curr Sci 109, 46-54.

[34] Wagner, B. L., and Lewis, L. C. (2000). Colonization of corn, Zea mays, by the entomopathogenic fungus Beauveria bassiana. Applied and Environmental Microbiology 66, 3468-3473. 